\title{
Carcinogenesis in Inflammatory Bowel Disease
}

\author{
Laszlo Herszenyi Pal Miheller Zsolt Tulassay \\ Semmelweis University, Second Department of Medicine, Hungarian Academy of Science, \\ Clinical Gastroenterology Unit, Budapest, Hungary
}

\section{Key Words}

Inflammatory bowel disease, carcinogenesis - Colorectal cancer in IBD, incidence $\cdot$ Colorectal cancer in IBD, risk factors $\cdot$ Colitis-associated colon carcinogenesis, molecular pathways $\cdot$ Surveillance colonoscopy

\begin{abstract}
Patients with longstanding ulcerative colitis (UC) and Crohn's disease (CD) have an increased risk of colorectal cancer (CRC). CRC accounts for approximately $15 \%$ of all deaths in patients with inflammatory bowel disease (IBD). The molecular pathway leading to CRC in IBD appears to differ from the wellknown adenoma-to-CRC sequence, given the fact that these cancers appear to arise from either flat dysplastic tissue or dysplasia-associated lesions or masses. The risk of CRC for patients with IBD increases by $0.5-1 \%$ yearly, $8-10$ years after diagnosis. Patients with a young age at disease onset, more extensive colitis, greater inflammatory burden, concomitant primary sclerosing cholangitis, and a family history of CRC are at greatest risk. Most cancers arise in pancolitis and there is little or no increased risk associated with proctitis while left-sided colitis carries an intermediate cancer risk. The CRC risk in patients with colonic CD is similar to that of UC. Colonic dysplasia is a precursor to CRC in IBD. There is no clear evidence that surveillance colonoscopy prolongs survival in
\end{abstract}

patients with extensive colitis. Newer endoscopic and molecular techniques are being assessed for their effectiveness in augmenting conventional surveillance.

Copyright $\odot 2007$ S. Karger AG, Basel

\section{Introduction}

Both ulcerative colitis (UC) and Crohn's disease (CD) are associated with an increased risk for developing colorectal cancer (CRC) and precancerous dysplastic epithelial changes. Knowledge of CRC risk in patients with inflammatory bowel disease (IBD) is still inadequate, despite the obvious conclusion that this is one of the most frightening aspects of the diagnosis of IBD [1].

\section{Incidence of Colorectal Cancer in Inflammatory Bowel Disease}

Although IBD contributes only $1-2 \%$ to all cases of CRC, the mortality rate in patients with a diagnosis of CRC in the setting of IBD is higher than of those afflicted with sporadic cases. CRC accounts for approximately $15 \%$ of all deaths in IBD patients $[2,3]$. The risk of CRC for people with IBD increases by $0.5-1 \%$ yearly, $8-10$

\section{KARGER}

Fax +4161306 1234

E-Mail karger@karger.ch

www.karger.com
(C) 2007 S. Karger AG, Basel

0257-2753/07/0253-0267\$23.50/0

Accessible online at:

www.karger.com/ddi
Laszlo Herszenyi, MD, $\mathrm{PhD}$

Second Department of Medicine

Semmelweis University Budapest

Szentkiralyi str. 46, HU-1088 Budapest (Hungary)

Tel./Fax +36 12660 816, E-Mail hersz@bel2.sote.hu 
Table 1. Risk factors for CRC in IBD

Duration of disease

Anatomic extent of disease

Age at onset

Disease activity

Family history of CRC

Primary sclerosing cholangitis

Table 2. Markers of malignant transformation and progression in IBD

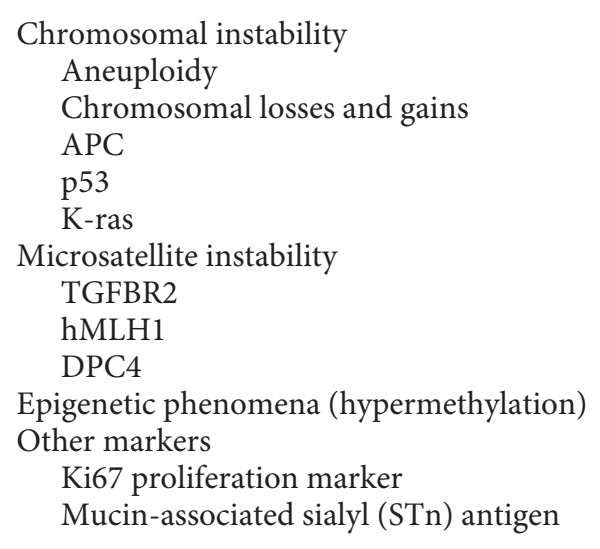

years after diagnosis. A meta-analysis of published studies reporting a CRC risk in UC shows the risk for any patients with colitis to be $2 \%$ at 10 years, $8 \%$ at 20 years, and $18 \%$ after 30 years of disease [4]. Adenocarcinoma of the small bowel is extremely rare, compared with adenocarcinoma of the colon. The CRC risk in patients with colonic $\mathrm{CD}$ is similar to that of $\mathrm{UC}$, and thus the guidelines for UC should be equally applicable to such patients with $\mathrm{CD}[5]$.

\section{Risk Factors for Colorectal Cancer in Inflammatory Bowel Disease}

Several factors have been suggested to be associated with a higher risk of CRC in patients with IBD (table 1). The magnitude of CRC risk increases with early age at IBD diagnosis, longer duration of symptoms, and extent of the disease, with pancolitis having a more severe inflammation burden and risk of the dysplasia-carcinoma cascade $[6,7]$. A family history of CRC is also a risk factor; patients with UC and CD with a first-degree relative with CRC have a relative risk of 2.5 and 3.7, respectively, for developing CRC [8]. Patients with concomitant primary sclerosing cholangitis are at higher risk for CRC. The absolute cumulative risk of cancer or dysplasia in this subset of patients has been estimated to be $9 \%$ after 10 years, $31 \%$ after 20 years, and $50 \%$ after 25 years of colitis $[9,10]$.

\section{Molecular Pathways of Colitis-Associated Colon Carcinogenesis}

The molecular pathway leading to CRC in IBD appears to differ from the well-known adenoma-to-CRC sequence, given the fact that these cancers appear to arise from either flat dysplastic tissue or dysplasia-associated lesions or masses (DALMs) [11, 12]. An important model for colon carcinogenesis in IBD follows progression from an absence of dysplasia, to indefinite dysplasia, to lowgrade dysplasia, on to high-grade dysplasia, and ultimately to invasive CRC [13]. APC loss of function is much less frequent in colitis-associated cancer and usually occurs later in the pathways to carcinoma than in sporadic CRC. Loss of p53 gene function occurs early in the pathway as tissue progresses toward dysplasia and cancer, and is not the final step as in sporadic CRC. Any particular genetic alteration that demonstrates a preferential or increased expression in neoplastic (dysplasia and/or cancer) tissues is potentially useful and might be thought of as a marker of cancer progression [14]. Many markers have been evaluated in this way, as listed in table 2. However, there is no consensus as to how, or even whether, these markers of cancer risk should be incorporated into clinical management of patients with long-standing IBD.

\section{Surveillance Colonoscopy}

Cancer surveillance in both UC and CD rests upon the detection of dysplasia. If a DALM was found at colonoscopy, immediate colectomy revealed cancer in $43 \%$ of patients regardless of the grade of dysplasia in the DALM. When high-grade dysplasia in flat mucosa was the initial discovery, immediate surgery revealed carcinoma in $42-$ $67 \%$ of the colectomy specimens. Thus, whenever a DALM or high-grade dysplasia is identified and confirmed by two expert gastrointestinal pathologists, this is a strong indication for colectomy [15]. Surveillance colonoscopies should be performed when the disease is in re- 
mission. All patients should have a screening colonoscopy after $8-10$ years that will also clarify disease extent. Regular surveillance should begin after 8-10 years from onset of symptoms for pancolitis and after 15-20 years for left-sided disease. As the risk of CRC increases exponentially with time, there should be a decrease in the screening interval with increasing disease duration. Two to four random biopsy specimens every $10 \mathrm{~cm}$ from the entire colon should be taken with additional samples of suspicious areas. Patients with primary sclerosing cholangitis represent a subgroup at a higher risk of cancer and they should have annual colonoscopy $[15,16]$. There is evidence that cancers tend to be detected at an earlier stage in patients who are undergoing surveillance. There is indirect evidence that surveillance is likely to be effective at reducing the risk of death from IBD-associated carcinoma and indirect evidence that it may be acceptably cost-effective [17].

Chromoendoscopy may prove to be a more efficient way to biopsy the colon. Chromoendoscopy not only al- lows for better differentiation between neoplastic and non-neoplastic changes in the colon but also improves early diagnosis of CRC [18].

Sampling errors in surveillance colonoscopies do occur and patients still can develop CRC despite routine follow-up. It has been suggested that chromosomal instability involves essentially the entire colon when dysplasia or CRC is present in patients with IBD. The genomic instability is present in non-dysplastic mucosa of UC patients with dysplasia or cancer, but not in patients without dysplasia or cancer. This may allow for simple rectal biopsies to be performed to help distinguish patients with UC who are likely to have dysplasia from those who are not [19].

Another promising approach might be to study global gene expression profiles using cDNA microarray technology. This technology is able to distinguish between sporadic adenomas and colitis-associated neoplasms, and therefore holds great promises for the future of molecular diagnostics in IBD [20].

\section{References}

1 Munkholm P: Review article: the incidence and prevalence of colorectal cancer in inflammatory bowel disease. Aliment Pharmacol Ther 2003;18(suppl 2):1-5.

-2 Itzkowitz S, Harpaz N: Diagnosis and management of dysplasia in patients with inflammatory bowel disease. Gastroenterology 2004;126:1634-1648.

3 Vagefi PA, Longo WE: Colorectal cancer in patients with inflammatory bowel disease. Clin Colorectal Cancer 2005;4:313-319.

4 Eaden JA, Abrams KR, Mayberry JF: The true risk of colorectal cancer in ulcerative colitis: a meta-analysis. Gastroenterology 2001;48:526-535.

-5 Carter MJ, Lobo AJ, Travis SP: Guidelines for the management of inflammatory bowel disease in adults. Gut 2004;53(suppl 5):V1V16.

-6 Rutter MD, Saunders BP, Wilkinson KH, Rumbles S, Schofield G, Kamm MA, Williams CB, Price AB, Talbot IC, Forbes A: Severity of inflammation is a risk factor for colorectal neoplasia in ulcerative colitis. Gastroenterology 2004;126:451-459.

7 Krok KL, Lichtenstein GR: Colorectal cancer in inflammatory bowel disease. Curr Opin Gastroenterol 2004;20:43-48.

8 Askling J, Dickman PW, Karlen P, Brostrom O, Lapidus A, Lofberg R, Ekbom A: Family history as a risk factor for colorectal cancer in inflammatory bowel disease. Gastroenterology 2001;120:1356-1362.
9 Soetikno RM, Lin OS, Heidenreich PA, Young HS, Blackstone MO: Increased risk of colorectal neoplasia in patients with primary sclerosing cholangitis and ulcerative colitis: a meta-analysis. Gastrointest Endosc 2002; 56:48-54.

10 Velayos FS, Loftus EV, Jess T, Harmsen WS, Bida J, Zinsmesiter AR, Tremaine WJ, Sandborn WJ: Predictive and protective factors associated with colorectal cancer in ulcerative colitis: a case-control study. Gastroenterology 2006;130:1941-1949.

11 Itzkowitz S: Colon carcinogenesis in inflammatory bowel disease. J Clin Gastroenterol 2003;36(suppl 1):S70-S74.

12 Harpaz N: Adenoma-like dysplastic polyps in inflammatory bowel disease. Pathol Case Rev 2004;9:135-141.

13 Thomas T, Nair P, Dronfield MW, Mayberry JF: Management of low- and high-grade dysplasia in inflammatory bowel disease: the gastroenterologists' perspective and current practice in the United Kingdom. Eur J Gastroenterol Hepatol 2005;17:1317-1324.

14 Schulmann K, Mori Y, Croog V, Yin J, Olaru A, Sterian A, Sato F, Wang S, Xu Y, Deacu E, Berki AT, Hamilton JP, Kan T, Abraham JM, Schmiegel W, Harpaz N, Meltzer SJ: Molecular phenotype of inflammatory bowel disease-associated neoplasms with microsatellite instability. Gastroenterology 2005;129: $74-85$.
15 Itzkowitz SH, Present DH: Consensus conference: colorectal cancer screening and surveillance in inflammatory bowel disease. Inflamm Bowel Dis 2005;11:314-321.

16 Rubin DT, Kavitt RT: Surveillance for cancer and dysplasia in inflammatory bowel disease. Gastroenterol Clin North Am 2006;35: 581-604.

17 Collins PD, Mpofu C, Watson AJ, Rhodes JM: Strategies for detecting colon cancer and/or dysplasia in patients with inflammatory bowel disease. Cochrane Database Syst Rev 2006;2:CD000279.

18 Geboes K: What are the important endoscopic lesions for detection of dysplasia in inflammatory bowel disease? Aliment Pharmacol Ther 2006;24(suppl 3):50-55.

19 Chen R, Rabinovitch PS, Crispin DA, Emond MJ, Koprowicz KM, Bronner MP, Brentnall TA: DNA fingerprinting abnormalities can distinguish ulcerative colitis patients with dysplasia and cancer from those who are dysplasia/cancer-free. Am J Pathol 2003;162: 665-672.

20 Selaru FM, Xu Y, Yin J, Zou T, Liu TC, Mori Y, Abraham JM, Sato F, Wang S, Twigg C, Olaru A, Shustova V, Leytin A, Hytiroglou P, Shibata D, Harpaz N, Meltzer SJ: Artificial neural networks distinguish among subtypes of neoplastic colorectal lesions. Gastroenterology 2002;122:606-613. 